\title{
Uma plataforma para construção de arquiteturas pedagógicas para a aprendizagem de LIBRAS
}

\author{
Luiz Fernando Reinoso ${ }^{1}$, Renan Freitas de Almeida ${ }^{2}$, Orivaldo de Lira Tavares ${ }^{2}$ \\ ${ }^{1}$ Coordenadoria de informática - Instituto Federal de Educação, ciência e Tecnologia do \\ Espírito Santo (IFES) \\ Av. Arino Gomes Leal, n 1700 - 29.700-660 - Colatina - ES - Brasil \\ ${ }^{2}$ Departamento de Informática \\ Universidade Federal do Espírito Santo (UFES) - Vitória, ES - Brasil. \\ luizfreinoso@gmail.com, ralmeida@ifes.edu.br, tavares@inf.ufes.br
}

\begin{abstract}
This work deals with the creation of a platform for creating and use of pedagogical architectures for LIBRAS learning, dedicated to apprentices in training as interpreters in translation and interpretation of signs LIBRAS. With the platform Builder Architectures Pedagogic (CAP), the teacher along with his apprentices can perform collaborative and individual learning activities. This article focuses on software development, creation and use of pedagogical architectures, flexible environments for learning and application of concepts of MOrFEu.
\end{abstract}

Keywords: pedagogical architectures, LIBRAS, interpreter, platafrom

Resumo. Este trabalho aborda a criação de uma plataforma para criação e uso de arquiteturas pedagógicas para aprendizagem de LIBRAS, dedicada a aprendizes em formação como intérpretes e tradutores de sinais LIBRAS. Com a plataforma Construtor de Arquiteturas Pedagógicas (CAP) o professor, com seus aprendizes, podem realizar atividades colaborativas e individuais de aprendizagem. Este artigo trata de desenvolvimento de software, criação e uso de arquiteturas pedagógicas, ambientes flexíveis para aprendizagem e aplicações de conceitos do MOrFEu.

Palavras-chave: Arquiteturas pedagógicas, LIBRAS, intérprete, plataformas

\section{Introdução}

A internet e a difusão de tecnologias digitais dentro do âmbito educacional tem sido intensificadas em diversas áreas de estudo de maneira notória. Isso vem aumentando o interesse para o uso de espaços virtuais, nos quais é possível realizar diferentes tipos de atividades, de forma dinâmica, flexível e colaborativa.

Este trabalho apresenta a implementação de uma plataforma para construção de Arquiteturas Pedagógicas (APs), utilizando tecnologias que contemplam recursos digitais para suporte a aprendizes de um curso técnico de "Tradução e Interpretação de LIBRAS”. 
A plataforma intitulada CAP (Construtor de Arquiteturas Pedagógicas com recursos digitais para aprendizagem de LIBRAS) foi desenvolvida para a criação e uso de arquiteturas pedagógicas (APs). As APs são suportes estruturantes à aprendizagem [Carvalho et al. 2005], focados na construção do conhecimento, de ideias construtivistas, de Jean Piaget, e de incentivo à autonomia, de Paulo Freire (1988). O modelo é oriundo de pesquisas aprofundadas nos elementos, propostas e conceitos do projeto MOrFEu [Menezes et al. 2008; Santos et al. 2010], um acrônimo para MultiOrganizador Flexível de Espaços Virtuais, onde são usadas estruturas computacionais flexíveis que possibilitam a edição e configuração de ambientes digitais.

Para o desenvolvimento da plataforma foi realizado um estudo etnográfico [Cervo et al. 2007], partindo de análises de documentos institucionais e atividades da disciplina 'Introdução a LIBRAS', ofertada a alunos do curso técnico. A partir desse levantamento inicial, foi feita a especificação de requisitos do sistema, a análise e o projeto da plataforma CAP, com a modelagem de banco de dados, as funcionalidades da plataforma e a implementação do protótipo.

A plataforma foi testada em relação ao seu aspecto funcional e usabilidade, com a participação de um professor intérprete (surdo) e seus aprendizes, que fizeram uso da plataforma em um laboratório de informática, efetivando as práticas de sala de aula em um ambiente digital. No teste de usabilidade, foram aplicadas as heurísticas de usabilidade de Nielsen [Nielsen 1993; Nielsen e Lorange 2007].

\section{LIBRAS e o intérprete}

Segundo dados da Secretaria Nacional de Promoção dos Direitos da Pessoa com Deficiência, 23,9\% da população residente no país em 2010 têm algum tipo de deficiência visual, auditiva, motora, mental ou intelectual. Desse total, 7,6\% é totalmente surda [Brasil 2012]. Estima-se que 60\% conhecem a Língua Brasileira de Sinais (LIBRAS), mas a comunicação com ouvintes é difícil [Coradine et al. 2004].

O intérprete LIBRAS é o profissional que domina a língua de sinais e a língua falada do país e é qualificado para desempenhar a função de intérprete [Brasil 2004]. A Lei $\mathrm{n}^{\circ} 12.319$, de $1^{\circ}$ de setembro de 2010 , dá reconhecimento legal a profissão de tradutor e intérprete de LIBRAS [Brasil 2010].

Segundo o MEC [BRASIL 2004 p.27], o intérprete está inteiramente envolvido na interação comunicativa, seja de forma cultural ou social, obtendo para si, poder completo e influência sobre o objeto e o produto da interação. O intérprete "processa a informação dada na língua fonte e faz escolhas lexicais, estruturais, semânticas e pragmáticas na língua alvo que devem se aproximar o mais apropriadamente possível da informação dada na língua fonte".

Guarinello et al. (2008) faz o seguinte comentário sobre os intérpretes:

[...]A inserção do intérprete na sala de aula pode ser entendida como uma maneira de minimizar as dificuldades dos surdos, já que, em geral, eles encontram uma desigualdade linguística dentro da sala de aula, por não ter uma língua compartilhada com seus colegas e professores ouvintes.[...]

A recente regulamentação da profissão de intérprete tem dado visibilidade ao ensino e aprendizagem de LIBRAS, o que nos faz refletir sobre a aplicação de 
V Congresso Brasileiro de Informática na Educação (CBIE 2016)

Anais dos Workshops do V Congresso Brasileiro de Informática na Educação (CBIE 2016)

metodologias e tecnologias para o suporte e aperfeiçoamento na formação desse novo profissional.

\section{Plataformas de ensino LIBRAS}

No estudo acerca de tecnologias para suporte a aprendizagem de LIBRAS, nota-se uma concentração na concepção de tecnologias voltadas a tradução bi-direcional entre emissor e receptor. Elas fazem uso de leitores de tela com avatares virtuais, como o ProDeaf e Handtalk [Santarosa 2014] que apresentam sinais Libras de forma animada, vídeos ou figuras segmentadas. Esses recursos, quando sequenciados corretamente, conseguem gerar traduções para sentenças e textos completos [Coradine et al. 2004][Sampaio et al. 2015]. O uso dessas tecnologias deve ser citado devido a atual facilidade de acesso e disponibilidade.

Durante o ciclo desta pesquisa foram realizadas buscas referenciais nos principais portais acadêmicos, como nos portais de periódicos da CAPES, ACM Digital Library e Google Acadêmico. A Figura 1 apresenta os resultados das buscas com o uso das sequências de palavras-chaves aplicadas de acordo com a ordem estabelecida a seguir: [1] "intérprete", "linguagem de sinais" e "plataforma"; em seguida a sequência [2] "plataforma", "LIBRAS" e "intérprete". As mesmas sequências de palavras-chave foram usadas para realizar pesquisas com as palavras traduzidas para a língua inglesa, com o intuito de levantar publicações internacionais sobre o tema.

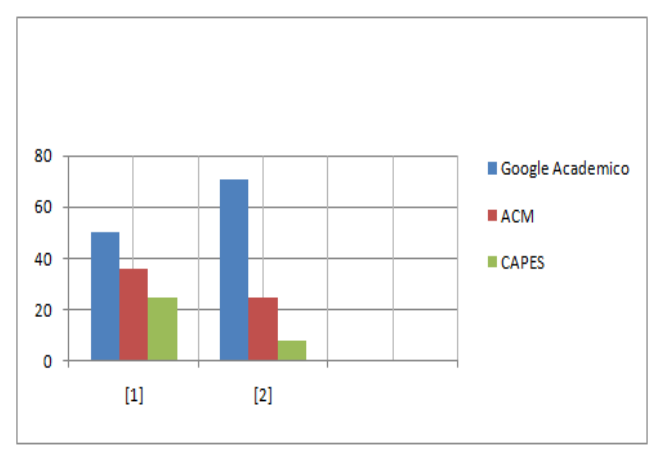

Figura 1. Resultados das pesquisas com as palavras-chaves

Desse levantamento, foi pré-selecionado um conjunto de quarenta artigos. Desse conjunto, doze artigos se destacaram no final da catalogação, leitura e fichamento dos mesmos. Três artigos apresentaram ferramentas que tratam diretamente do foco central da investigação, que são plataformas para treinamento e aperfeiçoamento de intérpretes em LIBRAS, valorizando aspectos de aquisição e aprendizagem dessa língua.

Acerca de ambientes dedicados ao ensino da LIBRAS, principalmente a aprendizes em formação ou extensão universitária, ficou claro a existência de poucos projetos. Entre eles estão o LIBRASWeb [Marcato et al. 2000], o graW-S [Costa et al. 2004] e o Deafword [Santos et al. 2014].

O LIBRASWeb e o Deafword focam na aprendizagem de sinais gestuais, de forma assíncrona e individual. Focam no uso de dicionários com sinais e pequenas sentenças em LIBRAS, destinado a qualquer interessado em aprender a linguagem brasileira de sinais. O LIBRASWeb é online e o Deafword é desktop. O graW-S é mais 
V Congresso Brasileiro de Informática na Educação (CBIE 2016)

Anais dos Workshops do V Congresso Brasileiro de Informática na Educação (CBIE 2016)

completo, sendo uma plataforma virtual de aprendizagem, com chat, forum, materiais de texto e wikis, objetivando a tradução dos conteúdos textuais apresentados em LIBRAS.

Essas ferramentas auxiliam na aprendizagem de LIBRAS, mas são inflexíveis, suas funcionalidades e recursos computacionais não podem ser configurados ou modificados por um professor.

\section{Um modelo de plataforma para criação de arquiteturas pedagógicas}

Esta seção inicia com a definição de arquiteturas pedagógicas usada neste trabalho; apresenta sucintamente um modelo para criação de espaços virtuais - o MOrFEu e a arquitetura de um Construtor de Arquiteturas Pedagógicas.

\subsection{Arquitetura pedagógica}

Reinoso e Tavares (2015) definem uma AP como uma estrutura didática constituída de: 1. objetivo pedagógico (o que aprender); 2. atividade(s) pedagógica(s) (o que fazer); 3. método pedagógico (como fazer cada atividade) e 4. recursos digitais (com que suporte).

\subsection{MOrFEu}

O MOrFEu - Multi-Organizador Flexível de Espaços Virtuais, garante um modelo para criação de sistemas que consiga fundamentar a produção de espaços virtuais/digitais de ensino, onde seus utilizadores conseguem gerenciar seu conhecimento, pautando-se em quatro aspectos principais: plasticidade, ergonomia, redução da repetição de trabalho e redução da sobrecarga cognitiva [Menezes et al. 2008]. Para compreender como o MOrFEu modela uma aplicação, deve-se conhecer seus elementos principais: a Unidade de Produção Intelectual (UPI) e o Veículo de Comunicação (VCom).

Segundo Nascimento et al. (2012), UPI é uma propriedade que formaliza as atividades do usuário, criada para cada texto (multimídia) produzido por ele, de modo que uma mesma UPI possa ser publicada em diferentes formas de apresentação. Para tanto, faz-se necessária uma espécie de template que consiga padronizar um conteúdo, facilitando a apresentação e utilização da parte visual.

A composição de várias UPIs é tratada como um Veículo de Comunicação (VCom). Para exemplo, podemos imaginar um caderno de anotações colaborativo como um VCom. Cada texto novo, escrito nesse caderno, é uma nova UPI criada e inserida por uma pessoa. O caderno, em si, é um VCom. Um template é a forma como os elementos que compõem a UPI são distribuídos no espaço, a coloração deles e a forma como as UPIs que compõem o VCOM são acessadas e visualizadas.

\subsection{Projeto de um Construtor de Arquiteturas Pedagógicas (CAP)}

No desenvolvimento da plataforma CAP e dos recursos digitais de suporte as APs, com foco na aprendizagem de LIBRAS, foi adotado o modelo de processo de software cascata [Pressman 2011]. O paradigma de desenvolvimento usado foi orientado a objetos, o que tornou a relação entre os objetos deste sistema interativa e dinâmica [Sommerville 2007].

A Figura 2 apresenta a arquitetura da CAP. Com o uso da CAP, o professor pode criar uma AP, configurando seus recursos. Cada nova AP constitui-se de UPIs e recursos digitais. As UPIs internas a AP definem o objetivo pedagógico, as atividades e 
V Congresso Brasileiro de Informática na Educação (CBIE 2016)

Anais dos Workshops do V Congresso Brasileiro de Informática na Educação (CBIE 2016)

sua metodologia. Essas UPIs internas são organizadas em um VCom (com UPIs e os respectivos recursos digitais) que compõe a AP.

Plataforma CAP

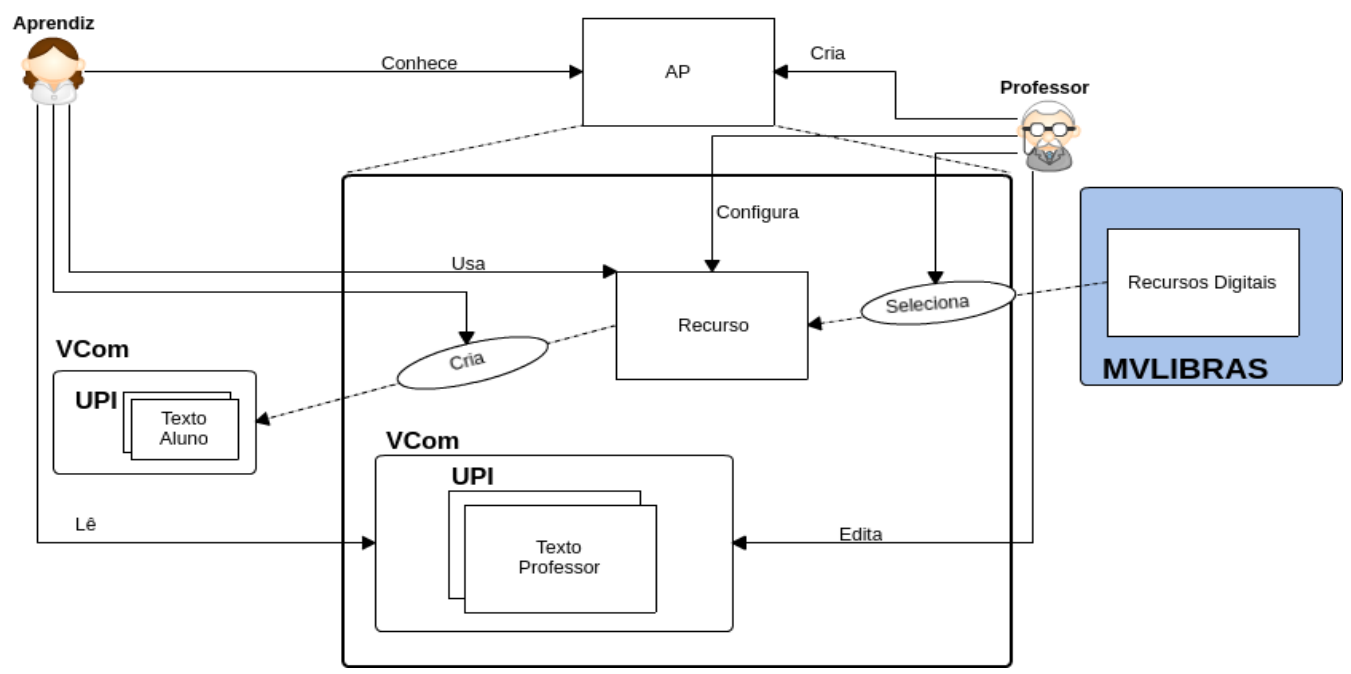

Figura 2. Arquitetura da plataforma CAP.

Os recursos digitais selecionados e configurados pelo professor, são agregados a sua AP. O professor pode ajustar as UPIs internas da AP quando desejar. Os recursos digitais, configurados pelo professor, dão suporte aos alunos no desenvolvimento das atividades.

Os RDs (Recursos Digitais) foram implementados de acordo com a demanda do professor. Por serem externos às APs como mostrado na Figura 2, quando um novo recurso digital é criado/atualizado ele não afeta as composições dos alunos (UPIs externas) e professores (UPIs internas), pois quando o professor seleciona e configura o recurso, essas informações são armazenadas em uma instância do recurso criada para a nova AP. Esse processo ajuda nas etapas de manutenção e atualização do CAP, sem prejuízos nas APs existentes.

\subsubsection{CAP - Construtor de arquiteturas pedagógicas com recursos digitais para aprendizagem de LIBRAS}

Para a turma do curso técnico de 'Introdução a LIBRAS', os recursos elicitados pelo professor foram inseridos em uma biblioteca denominada Movimento Virtual LIBRAS (MVLIBRAS), como mostrado na Figura 2. A junção do modelo CAP e esta biblioteca deram origem à plataforma CAP, usada pelo professor e por seus alunos.

A partir da definição da arquitetura do CAP, observa-se que a mesma pode ser usada para a construção de APs para qualquer área de conhecimento. A única alteração necessária é a substituição ou complementação da biblioteca de recursos digitais para oferecer RDs adequados às APs dessa nova área.

Dessa forma uma biblioteca com recursos digitais para trabalhar o contexto de história, por exemplo, bastaria substituir/atualizar/implementar recursos adicionais na MVLIBRAS. Assim seria possível a criação e uso de arquiteturas pedagógicas para aprendizagem de história. 
O objetivo da CAP é permitir a criação de arquiteturas pedagógicas, possibilitando a criação e uso de APs. Com base no modelo de AP apresentado [Reinoso e Tavares 2015], e após interações com o professor intérprete do curso técnico de "Tradução e interpretação LIBRAS", definiu-se as seguintes APs que a plataforma CAP deve criar inicialmente:

- APAVeL - Arquitetura Pedagógica para Aprendizagem de Verbos em LIBRAS: o objetivo pedagógico da AP é a aprendizagem sobre a execução da sinalização gestual animada de verbos em LIBRAS. A atividade associada é: cada usuário dessa AP deve fazer a gesticulação animada de verbos de uma lista de verbos. A metodologia é: gravar a gesticulação animada de cada verbo. Os recursos digitais alocados e disponíveis na AP permitem: gravar em vídeo as gesticulações.

- $\mathrm{APAGeV}$ - Arquitetura pedagógica para aprendizagem da gesticulação animada de verbos em LIBRAS: o objetivo pedagógico dessa AP é: a aprendizagem da interpretação de verbos sinalizados em LIBRAS. A atividade prevista aqui é: escolher e visualizar verbos sendo sinalizados em LIBRAS. A metodologia: pesquisar e buscar a datilologia e gesticulação de verbos do Português em LIBRAS, contidos dentro de bibliotecas e dicionários. Os recursos digitais disponíveis na AP ajudam na busca por sinais e visualização de palavras sinalizadas em LIBRAS.

- APTGeS - Arquitetura pedagógica para tradução e gesticulação de sentenças: o objetivo pedagógico da AP é a aprendizagem da tradução de sentenças em Português para LIBRAS gestual. A atividade: os alunos fazem a tradução de uma sentença em Português para LIBRAS gesticulada, traduzindo e sinalizando simultaneamente. A metodologia: uma sentença escrita pelo professor é passada para os aprendizes realizarem sua tradução e gesticulação em LIBRAS. A AP aloca recursos digitais para gravar a sinalização em LIBRAS das sentenças em Português.

- APIL - Arquitetura pedagógica para interpretação visual em LIBRAS: o objetivo pedagógico é a aprendizagem da interpretação da LIBRAS gesticulada e tradução para o Português escrito. A atividade: os alunos devem interpretar gestos de um vídeo do professor em LIBRAS e escrever a tradução da interpretação em Português. A metodologia: os aprendizes visualizam um texto sinalizado em LIBRAS, o interpretaram e transcrevem a tradução do texto para Português. Os recursos digitais para esta AP: visualizador de vídeos e editor de texto.

Os recursos que compõem a biblioteca MVLIBRAS:

- Captura de sinais LIBRAS: permite a gravação de sinais LIBRAS, com o uso de webcam.

- Busca de palavras LIBRAS: recurso para navegação nos vídeos de palavras LIBRAS dentro da plataforma.

- Conversor para datilologia: permite a conversão de uma sequência de letras que compõem um texto escrito para configurações de mão correspondentes. Esse 
V Congresso Brasileiro de Informática na Educação (CBIE 2016)

Anais dos Workshops do V Congresso Brasileiro de Informática na Educação (CBIE 2016)

processo de conversão de letras de texto escrito para as correspondentes configurações de mão é denominado de datilologia.

- Interpretador textual: permite a tradução de palavras, de um texto escrito, para LIBRAS, apresentando o gestual animado correspondente.

- Anexação de arquivos: permite ao professor disponibilizar arquivos aos alunos, para que eles possam efetuar o download dos mesmo.

- Edição de textos: permite ao professor/aluno editar textos escritos.

- Gravação de textos sinalizados em LIBRAS, na forma gestual animada: permite a gravação de textos sinalizados em LIBRAS a partir de textos escritos, definidos pelo professor.

- Visualização de texto na forma gestual animada (vídeo) : permite ao aluno ver um vídeo preparado pelo professor, com um texto na forma gestual animada, de modo a interpretá-lo e traduzi-lo para o português.

A plataforma CAP foi implementada utilizando o web framework Django 1.6.5 [Django 2016] que utiliza a linguagem Python, o que possibilitou a implantação da plataforma em ambiente web, com base de dados MySQL 5.6 [MYSQL 2016].

\section{Análise e testes realizados}

Para a avaliação, foram realizados testes de usabilidade da plataforma CAP em função das APs criadas nela, utilizando-se as heurísticas propostas por Nielsen [Nielsen, 1993; Nielsen e Loranger 2007]. Foi realizado em conjunto, um teste funcional para verificar se a plataforma desenvolvida está cumprindo seu papel, do ponto de vista dos usuários, com um teste de sistema em formato prescritivo, onde avaliamos a funcionalidade do ambiente virtual e sua relação com os seus utilizadores.

Os testes foram realizados em uma aula de 50 minutos, com o professor e 36 alunos, em um laboratório de informática com 40 computadores munidos de câmeras digitais, microfone e acesso à internet. O navegador utilizado foi o Mozilla Firefox, versão 36.

\subsection{Teste de usabilidade}

Os testes realizados na plataforma CAP partem do uso de técnicas que permitem analisar os dados levantados por meio de questionários sobre o perfil dos usuários e o uso do sistema. Nesses testes, buscou-se obter informações acerca da efetividade do software, sob o ponto de vista de seus usuários [Cybis et al. 2007].

O questionário de usabilidade nos moldes apresentados, demonstrou que 13,88\% dos alunos relatam existir diferenças entre a prática de suas atividades de sala de aula habituais e a realização delas no sistema. Um percentual de 5,66\% dos usuários apresentaram alguma dificuldade em realizar atividades virtuais de modo geral. A pontuação média atribuída pelos usuário para a usabilidade geral foi de 88/100.

A mudança do método de ensino, antes praticado estritamente sem uso da tecnologia, pode explicar o sucesso alcançado, pois esses testes acontecem no início de um processo de difusão e implantação de tecnologia, onde faltam similares para um comparativo. 
V Congresso Brasileiro de Informática na Educação (CBIE 2016)

Anais dos Workshops do V Congresso Brasileiro de Informática na Educação (CBIE 2016)

\subsection{Teste funcional}

O teste funcional é também chamado de teste baseado em especificações ou teste caixapreta [Pezzé 2008]. Os alunos foram convidados a utilizar a plataforma CAP, com intuito de encontrar melhorias entre os recursos da biblioteca MVLIBRAS e das APs criadas pelo professor, que também avaliou a ferramenta. Das disposições gerais dadas pelos alunos e seu professor, após avaliação dos dados gerados por eles nos testes, temse:

- o sistema funciona inteiramente com os recursos digitais;

- falta recursos de inclusão, como sistemas de tradução com avatar;

- os alunos acreditam que ter o recurso de tradução com avatar ajudaria e até mesmo incentivaria a inclusão da comunidade de surdos na plataforma. Ressaltase que os alunos da turma participante desta pesquisa são todos ouvintes.

O teste funcional revelou que os usuários da CAP sugerem algumas melhorias dos recursos digitais. A CAP em si funcionou adequadamente, mas é visível a dependência das APs em relação aos recursos especialmente desenvolvidos para atendêlas, o que justifica a necessidade de ajustes/adaptações de cada recurso alocada para uma $\mathrm{AP}$, por meio de ações de configuração feitas pelo professor (demonstrado na Figura 2).

\section{Considerações finais}

O conceito de arquiteturas pedagógicas, usado para a concepção do modelo estrutural CAP, ajudou a planejar e estruturar atividades pedagógicas, de modo que, seguindo uma metodologia e usando os recursos digitais disponíveis, os alunos possam alcançar um objetivo de aprendizagem planejado pelo professor.

Os conceitos de UPI, VCom e template, do projeto MOrFEU, permitiram a implementação de uma plataforma para construção de APs que incorpora de modo inovador os conceitos de flexibilidade, reuso e persistência dos dados (UPIs).

Constata-se que a CAP é versátil, pois a biblioteca de recursos digitais, como exemplificado no trabalho, pode ser trocada por outra biblioteca, com recursos digitais mais apropriados para outra área de aprendizagem, de modo a permitir a criação de APs para a aprendizagem nessa outra área. Assim, a arquitetura da CAP é flexível e permite a criação de APs para outros assuntos.

A plataforma CAP alcançou índices de usabilidade e funcionalidade aceitáveis, tendo desempenhado de modo satisfatório a sua função. Uma projeção futura para a ferramenta, com embasamento no $\mathrm{MOrFEu}$, é permitir ao professor criar o recurso digital que planejar, a partir da composição de recursos digitais menores, sem necessidade de conhecer linguagens de programação. Conhecendo os dados de entrada e de saída de cada recurso digital existente, ele poderá criar novos recursos a partir da composição/agregação dos recursos digitais existentes na biblioteca.

Outra proposta de trabalho futuro é que cada AP possa ser acessada de modo personalizado pelo aprendiz, com templates que possam ser selecionados de acordo com o perfil do aluno (aluno surdo, aluno ouvinte, aluno avançado etc.), ao invés de ter um template estático como é hoje. 
V Congresso Brasileiro de Informática na Educação (CBIE 2016)

Anais dos Workshops do V Congresso Brasileiro de Informática na Educação (CBIE 2016)

\section{Referencias}

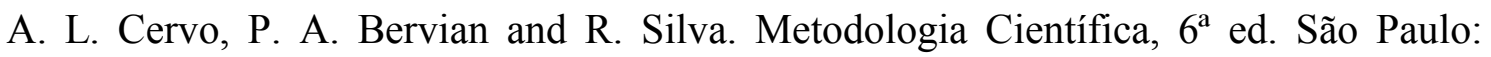
Pearson Prentice Hall. 2007.

C. S. Menezes, R. A. Nevado, A. N. C. Jr, L. N. Santos. MOrFEu - Multi-Organizador Flexível de Espaços Virtuais para Apoiar a Inovação Pedagógica em EAD. In XIX Simpósio Brasileiro de Informática na Educação. páginas 451-460, 2008.

C. V. Nascimento, C. S. Menezes and O. L. Tavares. Uma arquitetura de acessibilidade par ambientes virtuais. In: Memorias del XVII Congreso Internacional de Informática Educativa, TISE, Santiago-Chile, pages 353-358, 2012.

DJANGO. "Django Overview", Disponível em: https://www.djangoproject.com/start/overview/ , 2016. Acesso em: 26 Jan. 2016.

I. Sommerville. Engenharia de Software, ed. 8, São Paulo: Pearson Assison-Wesley. 2007.

J. A. M. Nascimento, S. A. Amaral. Avaliação de usabilidade na internet. Brasília: Thesaurus. 2010.

J. Nielsen, H. Loranger. Usabilidade na web: Projetando Websites com qualidade. Rio de Janeiro: Editora Elseiver. 2007.

J. Nielsen. Usability Engineering. Academic Press. 1993.

L. F. Reinoso and O. L. Tavares. MVLIBRAS: ambiente digital para comunidades de aprendizagem com recursos inclusivos para surdos. In: Anais do XXVI Simpósio Brasileiro de Informática na Educação. Maceió-Alagoas. 2015.

L. N. Santos, A. N. C. Jr, C. S. Menezes. MOr-FEu: Criando Ambientes Virtuais Flexíveis na WEB para mediar a colaboração. In Congresso Iberoamericano de Informática Educativa. páginas 114-121, 2010.

M. J. S. Carvalho, R. A. Nevado, C. S. Menezes. Arquiteturas Pedagógicas para Educação a Distância: Concepções e Suporte Telemático. In XVI Simpósio Brasileiro de Informática na Educação. páginas 351-360, 2005.

M. Pezzè, M. Young. Teste e análise de software: processos, princípios e técnicas, Porto Alegre: Bookman, 512p. 2008.

MYSQL. About MySQL, Disponível em: http://www.mysql.com/about/. 2016. Acesso em: 26 Jan. 2016.

P. Freire. Pedagogia da Autonomia: saberes necessários à prática educativa. Rio de Janeiro: Paz e Terra. 1998.

R. S. Pressman. Engenharia de Software: Uma abordagem Profissional ed. 7, Porto Alegre: AMGH, p. 780. 2011.

W. Cybis, A. H. Beitol, R. Faust. Ergonomia e usabilidade: Conhecimentos, métodos e aplicações. São Paulo: Editora Novatec. 2007. 